\title{
ELECTRICAL CONDUCTANCE OF HYDROGEN CHLORIDE IN DIMETHYLSULPHOXIDE AT $25^{\circ} \mathrm{C}^{*}$
}

\author{
J. A. Bolzan and A. J. Arvía \\ Instituto Superior de Investigaciones, División Electroquímica, Facultad de Ciencias \\ Exactas, Universidad Nacional de La Plata, La Plata, Argentina
}

\begin{abstract}
The electrical conductance of hydrogen chloride solutions in DMSO at $25^{\circ} \mathrm{C}$ has been studied. The limiting molar conductance is $38 \cdot 7$ int $\mathrm{mho} \mathrm{cm}^{2} / \mathrm{mol}$. Conductivity data were interpreted with the Fuoss' theory for associated 1-1 type electrolytes. The association constant related to pair formation is $115.71 / \mathrm{mol}$. The mechanism of electrical conduction of $\mathrm{HCl}$ in DMSO at infinite dilution resembles that of other 1-1 type electrolytes in the same solvent, in which charges are transported by simple entities in a viscous continuum.
\end{abstract}

Résumé-On a étudié la conductivité électrique des solutions de chlorure d'hydrogène dans le DMSO à $25^{\circ} \mathrm{C}$. La conductivité limite molare est de $38,7 \mathrm{mho}$ int $\mathrm{cm}^{2} / \mathrm{mol}$. Les données expérimentalles de la conductivité furent interprétées d'après la théorie de Fuoss pour des électrolytes associé du type 1-1. La constante d'association liée à la formation de paires ioniques simple est 115,7 1/mol. Le méchanisme de la conduction électrique du $\mathrm{HCl}$ dans le DMSO à dilution infinie ressemble celui des autres électrolytes du type 1-1 dans le même dissolvant, puisque les charges sont transportées par des entités simples dans un milieu visqueux continu.

Zusammenfassung-Die elektrische Leitfähigkeit von Chlorwasserstofflösungen in DMSO bei $25^{\circ} \mathrm{C}$ wurde untersucht. Die Molargrenzkonduktanz is 38,7 int $\mathrm{mho} \mathrm{cm}^{2} / \mathrm{mol}$. Die Leitfähigkeitswerte wurden mittels die Fuosstheorie für Elektrolyte des 1-1 Typs gedeutet. Die Assoziationskonstante, auf die Paarbildung bezogen, is 115,7 1/mol. Der Mechanismus der elektrische Leitung von $\mathrm{HCl}$ in DMSO in unendlicher Lösung gleicht dem der Elektrolyte anderer 1-1 Type in selben Lösungsmittle, die Ladungen werden durch einfache Träger in kontinuirlichen viskosem Medium transportiert.

\section{INTRODUCTION}

HYDRoGEN chloride dissolves readily in dimethylsulphoxide (DMSO) as in other organic solvents, up to high concentrations of about $3-4 M, 1$ and in saturated solutions a white solid has been observed that has been characterized as an addition compound of both species. ${ }^{1,2}$

Solutions of $\mathrm{HCl}$ in DMSO with or without addition of supporting electrolytes have been used for studying the electrochemical evolution of hydrogen on the dme ${ }^{3}$ and on platinum electrodes ${ }^{4}$ and also in the measurements of emf of cells. However, a clear knowledge of the ionic species responsible for the electrical conductivity in the solution is still lacking and further studies are justified.

Preliminary results showed that the mechanism of electrical conduction of $\mathrm{HCl}$ in DMSO is different from that in aqueous media. At infinite dilution the molar limiting conductance found was about $40 \mathrm{int}$ mho $\mathrm{cm}^{2} / \mathrm{mol}^{1.5}$ This figure resembles very much the values found for the molar limiting conductances of other 1-1 electrolytes previously investigated ${ }^{6,7}$ although in that case (alkaline perchlorates) the salts obeyed the Fuoss-Onsager equation for non-associated electrolytes up to concentrations of about $2 \times 10^{-2} \mathrm{M}$, which seems not to be so in the present case.

It was then interesting to investigate further the electrical conduction mechanism and to compare the behaviour of $\mathrm{HCl}$ in DMSO with that in other solvents where ionic interactions, either dipole or of chemical type, may occur. ${ }^{8}$

* Manuscript received 2 January 1969. 


\section{Chemicals}

DMSO, pure grade, from Fluka or Hopkin \& Williams was employed. It was redistilled by the following procedure. To each bottle some $20 \mathrm{~g}$ of activated alumina were added with intermitent shaking for $48 \mathrm{~h}$. After decantation, the solvent was distilled under vacuum ( $4-5$ torr), neglecting $10 \%$ fractions as head and tail. The middle fraction was distilled again, less a $10 \%$ tail fraction, and was stored in tightly sealed containers. The specific conductivity was about $10^{-8}$ int $\mathrm{mho} / \mathrm{cm}$. The hydrochloric acid used was reagent grade.

\section{Solutions}

The stock solutions were made by bubbling gaseous $\mathrm{HCl}$ through the solvent. Concentrated sulphuric acid was dropped over hydrochloric acid. The gaseous $\mathbf{H C l}$ evolved was passed through several washing flasks to eliminate moisture and other impurities and bubbled through DMSO until a suitable concentration was reached. The exact value was then determined by acidimetry and argentometry. Working solutions were then prepared by diluting the stock solution with the solvent, making use of calibrated volumetric glassware.

\section{Instrumentation}

Conductivity measurements were made with an LKB model 3216 bridge, fitted with a Wagner earth, at frequencies of 1 and $2 \mathrm{KHz}$. This bridge has a range of 1 to $11,110 \Omega$ and a precision of $0 \cdot 1 \%$. To make it more versatile, external non-inductive decade resistance boxes were added, extending the range to $200 \mathrm{~K} \Omega$. With the high conductivity solutions where fractions of $1 \Omega$ had to be measured, a ten-turn Kohlrausch wire with a resistance of $7 \Omega$ was added to the bridge.

Three different Pyrex conductivity cells with platinum electrodes were employed. Their constants were $10.683 \mathrm{~cm}^{-1}$ (platinized); $0.1363 \mathrm{~cm}^{-1}$ (platinized) and 0.0239 $\mathrm{cm}^{-1}$ (bright). Values of the constants were determined at $25^{\circ} \mathrm{C}$ with standard solutions of $\mathrm{KCl}$ prepared according to Jones and Bradshaw. ${ }^{9}$ The specific conductances of these solutions were $L_{0.1 \mathrm{~N}}=0.0128862 \mathrm{int} \mathrm{mho} / \mathrm{cm} ; L_{0.01 \mathrm{~N}}=0.00141145 \mathrm{int} \mathrm{mho} / \mathrm{cm}$.

The temperature was controlled at $25^{\circ} \mathrm{C}$ to within $0.01^{\circ} \mathrm{C}$ with a Bühler Superthermostat of 14-1 capacity.

\section{RES ULTS}

Results obtained with solutions of different concentrations are summarized in Table 1. Conductivity data were corrected for the contribution of the solvent. Each measurement was made after thermal equilibrium, which took about $2 \mathrm{~h}$. No time effect was found, contrary to the case of $\mathrm{HCl}$ in other solvents like acetonitrile, ${ }^{10}$ benzonitrile ${ }^{11}$ or in the system iodine-pyridine. ${ }^{12}$ A shaking effect was observed, as in other ionic systems comprising organic solvents. ${ }^{13}$ In order to explain in some detail the mechanism of conduction, viscosity measurements were made for all the solutions employed.

\section{DISCUSSION}

Figure 1 shows a plot of the molar conductivity, $\Lambda$, against the square root of molar concentration, $c$. The function is not linear, but instead a smooth curve 
TABLE 1

\begin{tabular}{|c|c|c|c|c|c|}
\hline $\begin{array}{c}c \\
\mathbf{M}\end{array}$ & $\begin{array}{c}\eta \times 10^{2} \\
\mathrm{~g} / \mathrm{cms}\end{array}$ & 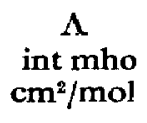 & $\gamma$ & $\begin{array}{c}\Lambda_{\eta}^{\prime} \\
\text { int mho } \\
\mathrm{cm}^{2} / \mathrm{mol}\end{array}$ & $f$ \\
\hline $5.383 \times 10^{-2}$ & $2 \cdot 086$ & $13 \cdot 55$ & 0.381 & $18 \cdot 87$ & 0.692 \\
\hline $4.306 \times 10^{-2}$ & $2 \cdot 080$ & $14 \cdot 67$ & 0.411 & $19 \cdot 53$ & $0 \cdot 710$ \\
\hline $2 \cdot 153 \times 10^{-2}$ & $2 \cdot 073$ & $18 \cdot 45$ & 0.508 & 22.05 & 0.764 \\
\hline $1.724 \times 10^{-2}$ & $2 \cdot 065$ & $19 \cdot 42$ & 0.533 & $22 \cdot 57$ & 0.790 \\
\hline $1.036 \times 10^{-2}$ & $2 \cdot 050$ & $22 \cdot 91$ & 0.623 & $25 \cdot 51$ & 0.813 \\
\hline $8.305 \times 10^{-3}$ & $2 \cdot 044$ & 23.93 & 0.649 & $26 \cdot 25$ & 0.828 \\
\hline $6.648 \times 10^{-3}$ & $2 \cdot 039$ & $25 \cdot 93$ & 0.701 & $28 \cdot 05$ & 0.839 \\
\hline $4.297 \times 10^{-3}$ & 2.036 & $27 \cdot 00$ & 0.725 & $28 \cdot 66$ & 0.866 \\
\hline $3.327 \times 10^{-3}$ & $2 \cdot 033$ & $29 \cdot 56$ & 0.792 & $31 \cdot 06$ & 0.876 \\
\hline $1.664 \times 10^{-3}$ & $2 \cdot 027$ & $32 \cdot 52$ & 0.865 & $33 \cdot 56$ & 0.907 \\
\hline $8.585 \times 10^{-4}$ & $2 \cdot 023$ & $34 \cdot 10$ & 0.902 & $34 \cdot 82$ & 0.931 \\
\hline $8 \cdot 337 \times 10^{-4}$ & 2.021 & $34 \cdot 11$ & 0.902 & $34 \cdot 82$ & 0.932 \\
\hline $4.179 \times 10^{-4}$ & $2 \cdot 018$ & 36.06 & 0.950 & $36 \cdot 55$ & 0.950 \\
\hline $1.716 \times 10^{-4}$ & $2 \cdot 014$ & $37 \cdot 00$ & 0.971 & $37 \cdot 30$ & 0.967 \\
\hline $8.350 \times 10^{-5}$ & $2 \cdot 011$ & $37 \cdot 77$ & 0.990 & $37 \cdot 97$ & 0.977 \\
\hline
\end{tabular}

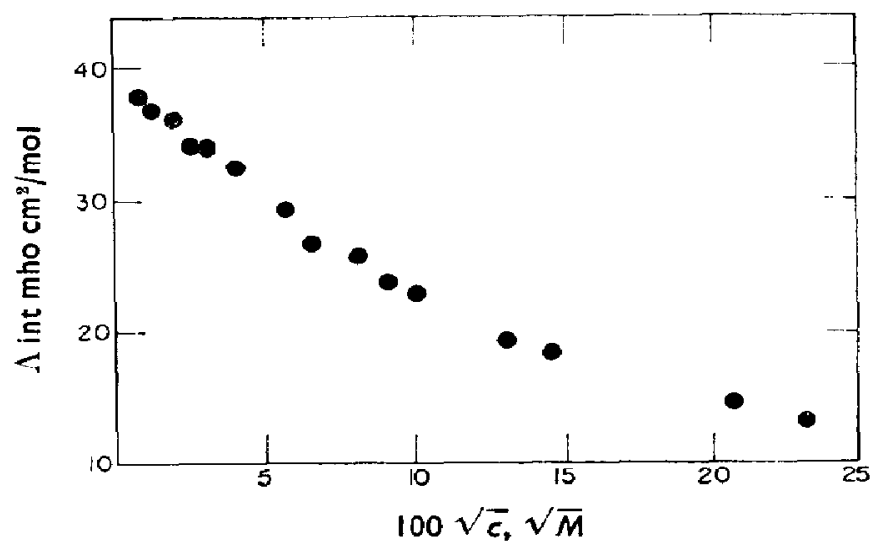

FIG. 1. Plot of $\Lambda$ vs $c^{1 / 2}$.

results. On the other side, taking conductivity data at the highest dilution, the limiting slope in the plot $\Lambda v s c^{1 / 2}$ has a value much larger than the one expected from Onsager's equation for a completely dissociated I-1 type electrolyte. In the latter case, at $25^{\circ} \mathrm{C}$, the Onsager theoretical slope is $55 \cdot 1$, while taking conductivity data at the highest dilution the experimental value is about 196. This fact shows that HCl does not behave in DMSO as a completely dissociated strong electrolyte, as distinct from other 1-1 type electrolytes, ${ }^{6.7}$

The simplest theory one can apply is the classical Arrhenius in the form of Ostwald's dilution law. However, it is not possible in this way to obtain with any good accuracy the molar limiting conductance nor the equilibrium constant for the electrolyte dissociation. But in any case, two points emerge from this approximation. First, the degree of dissociation, $\alpha$, varies from 0.3 for concentrated solutions to 0.99 for the most dilute and secondly, the dissociation constant, $K_{\mathrm{d}}$, is about $10^{-3} \mathrm{~mol} / 1$.

On the basis of these results, equations based on the Onsager theory were applied. For ionic systems in solvents with dielectric constants smaller than that of water, various methods of evaluation for $\Lambda_{0}$ and $K_{\mathrm{d}}$ are available, such as that of Fuoss and 
Kraus $^{14}$ and Fuoss and Shedlovsky, ${ }^{15}$ to be applied prior to the theory of Fuoss for the conductance of 1-1 associated electrolytes in dilute solutions. ${ }^{16}$ The Fuoss and Shedlovsky procedure was first chosen on account of being more suitable for values of $K_{\mathrm{d}}$ between $10^{-3}$ and 1.15 Shedlovsky's equation is

$$
\frac{1}{\Lambda S_{\mathrm{s}}}=\frac{1}{\Lambda_{0}}+\frac{c \Lambda S_{\mathrm{s}} f^{2}}{K_{\mathrm{d}} \Lambda_{0}^{2}}
$$

where at low concentrations $1 /\left(\Lambda S_{\mathrm{g}}\right)$ is a linear function of $c \Lambda S f^{2}$. The ordinate at origin is $1 / \Lambda_{0}$ and the slope is $1 / K_{\mathrm{d}}$. The $S_{\mathrm{g}}$ term is

$$
S_{\mathrm{s}}=\left[\frac{z}{2}+\sqrt{1+\left(\frac{z}{2}\right)^{2}}\right]^{2}
$$

where $z$ is an auxiliary variable defined by Fuoss, ${ }^{17}$

$$
z=\frac{S_{0}(c \Lambda)^{1 / 2}}{\Lambda_{0}^{3 / 2}}
$$

and $S_{0}$ is the Onsager coefficient. In (1), $f$ is the mean activity coefficient calculated from the Debye-Hückel limiting law. Results obtained with Shedlovsky's equation are

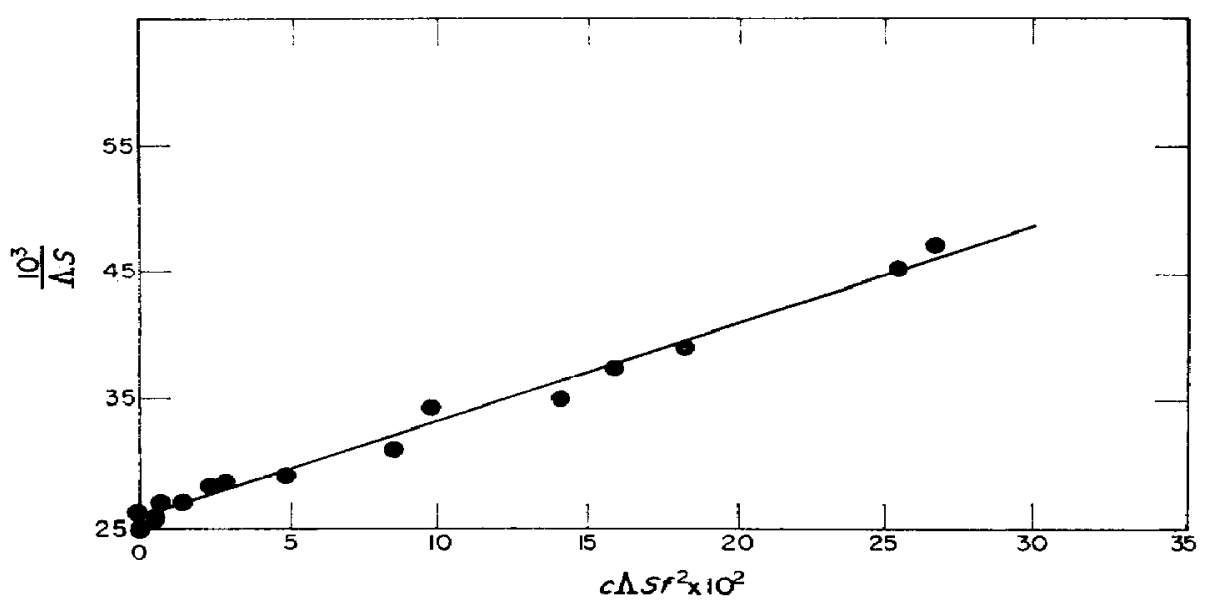

FIG. 2. Plot of equation (1).

shown in Fig. 2. Applying a least squares calculation, we find $\Lambda_{0}=38 \cdot 7$ int mho $\mathrm{cm}^{2} / \mathrm{mol}$ and $K_{\mathrm{d}}=1 / K_{\mathrm{a}}=8.8 \times 10^{-3} \mathrm{~mol} / 1$.

Application of Fuoss' theory

When association is not negligible the conductance of dilute solutions of $1-1$ electrolytes is better represented by the equation derived by Fuoss, ${ }^{16}$

where

$$
\Lambda_{\eta}=\Lambda_{0}-S(c \gamma)^{1 / 2}+E c \gamma \log c \gamma+J c \gamma-K_{\mathrm{a}} c \gamma f^{2} \Lambda_{\eta},
$$

$$
\Lambda_{\eta}=\Lambda(1+F c)
$$


and

$$
F=\frac{\frac{\eta-\eta_{0}}{\eta_{0}}-S_{\eta} c^{1 / 2}}{c}
$$

$\eta$ is the viscosity of the solution and $\eta_{0}$ that of the solvent, $S_{\eta}$ is the FalkenhagenDole coefficient, 18,19 which depends on the single ionic conductances, and $S, E$ and $J$ are parameters deduced from the theory. At constant temperature $S$ depends on $\kappa$ and on the macroscopic dielectric constant. $E$ and $J$ are at the same time functions of the product $\kappa a$, where $a$ is the ionic diameter and $\kappa$ the Debye-Hückel parameter. $J$ depends also on the $b$ parameter defined by Bjerrum. ${ }^{20}$ For the evaluation of $S, E$ and $J$, the basic equations of Fuoss's paper were applied. $J$ can be calculated assuming suitable values of $a$, as shown in Table 2. $\gamma$ is the ionic fraction of the

TABLE 2. VALUES OF $J$ FOR
DIFFERENT VALUES OF $a$ AT
\begin{tabular}{cc}
$25^{\circ} \mathrm{C}$ \\
\hline$a \times 10^{8}$ & $J$ \\
$\mathrm{~cm}$ & \\
\hline 1 & $48 \cdot 4$ \\
2 & 138.0 \\
3 & $179 \cdot 4$ \\
4 & $231 \cdot 6$ \\
5 & $280 \cdot 7$ \\
6 & 328.1 \\
\hline
\end{tabular}

species which actually contributes to the charge transport at a given concentration and is expressed as:

$$
\gamma=\frac{\Lambda}{\Lambda_{0} F(z)} .
$$

$F(z)$ is a function that has been tabulated by Fuoss for round values of $z$ from $0 \cdot 000$ to $0 \cdot 209 .{ }^{17} \quad K_{\mathrm{a}}$ is the association constant of the electrolyte and $f$ is the mean activity coefficient given by the Debye-Hückel equation corrected for the finite size of the ions. ${ }^{20}$

It is feasible to apply the Fuoss theory to solutions so dilute that $0 \leqslant \kappa a \leqslant 0 \cdot 2$. Assuming reasonable values for $a$ from $1 \times 10^{-8} \mathrm{~cm}$ to $3 \times 10^{-8} \mathrm{~cm}$, we conclude from Table 3 that all the concentrations studied fall within the scope of the theory for

TABle 3. Values of $k a$ for Different $a$ values

\begin{tabular}{cccc}
\hline $\begin{array}{c}c \times 10^{2} \\
M\end{array}$ & 2 & $a \times 10^{8}, \mathrm{~cm}$ & 6 \\
\hline 5.383 & 0.15 & 0.30 & 0.45 \\
4.306 & 0.14 & 0.27 & 0.41 \\
2.153 & 0.10 & 0.19 & 0.28 \\
1.724 & 0.08 & 0.17 & 0.25 \\
1.036 & 0.06 & 0.13 & 0.20 \\
0.8305 & 0.06 & 0.12 & 0.18 \\
0.6648 & 0.05 & 0.11 & 0.16 \\
0.4297 & 0.04 & 0.09 & 0.13 \\
\hline
\end{tabular}


$a=1 \times 10^{-8} \mathrm{~cm}$ and $a=2 \times 10^{-8} \mathrm{~cm}$. For $a=3 \times 10^{-8} \mathrm{~cm}$, only the most concentrated solutions are outside the theory.

As indicated by Fuoss, the calculation is made by successive approximations. In the present case we started with a $\Lambda_{0}$ value obtained by extrapolation of the Shedlovsky function. Later new values of $\Lambda_{0}$ were taken until a reasonably linear plot was obtained for the equation

$$
\frac{\Lambda_{\eta}+S(c \gamma)^{1 / 2}-E c \gamma \log c \gamma-\Lambda_{0}}{c \gamma}=\frac{\Lambda_{\eta}{ }^{\prime}-\Lambda_{0}}{c \gamma}=J-K_{\mathrm{a}} f^{2} \Lambda_{\eta} .
$$

Figure 3 shows a plot of (8), where $y$ is the left-hand side and $x$ is the second term of the right-hand side. The slope gives $K_{\mathrm{a}}=115.71 / \mathrm{mol}$ and from this value, we find it

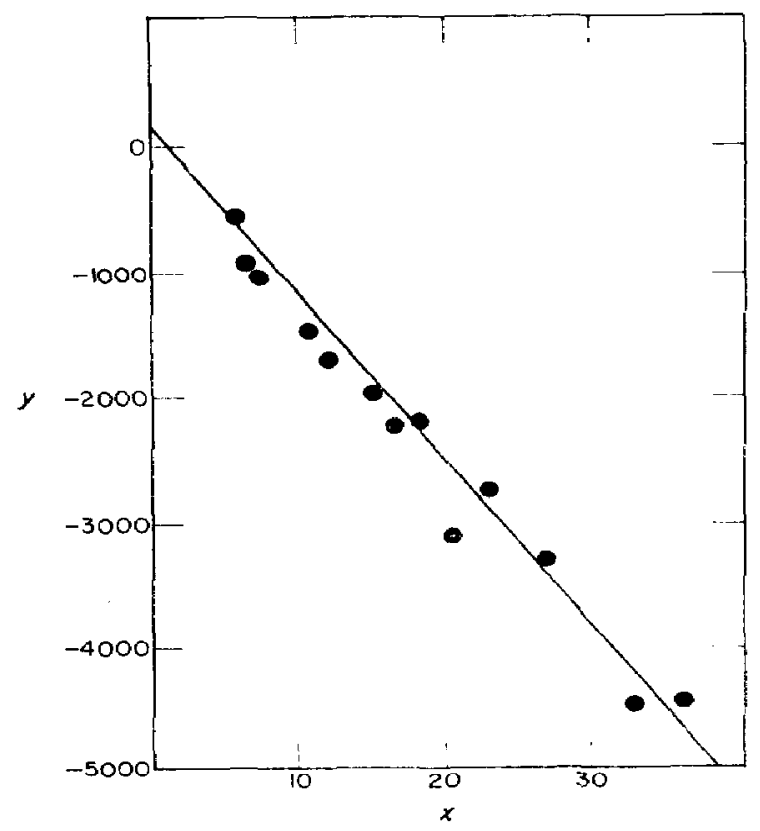

FIG. 3. Plot of equation (8).

results $K_{\mathrm{d}}=8.64 \times 10^{-3} \mathrm{~mol} / 1$, while the ordinate at the origin gives $J=160$. From the latter figure the mean ionic radius is $(2 \cdot 0 \pm 0 \cdot 3) \times 10^{-8} \mathrm{~cm}$, which agrees satisfactorily with the solvodynamic radius of the cation found by measurements of the diffusion coefficient of the solvated hydrogen ion in DMSO with the rotating disk electrode. ${ }^{2}$ Table 4 shows values of $K_{\mathrm{d}}$ and $\Lambda_{0}$ calculated by the different methods.

Table 4. Values of $K_{d}$ AND $\Lambda_{0}$ eValuated BY DIfFerent METHODS

\begin{tabular}{|c|c|c|}
\hline Method & $\begin{array}{c}K_{\mathbf{a}} \times 10^{3} \\
\mathrm{~mol} / 1\end{array}$ & $\frac{\Lambda_{0}}{\text { int } \mathrm{mho} \mathrm{cm}^{2} / \mathrm{mol}}$ \\
\hline $\begin{array}{l}\text { Ostwald's dilution law } \\
\text { Shedlovsky } \\
\text { Fuoss }\end{array}$ & $\begin{array}{l}1 \cdot 8 \\
8 \cdot 8 \\
8 \cdot 64\end{array}$ & $\begin{array}{l}40 \\
38 \cdot 7 \\
38 \cdot 4\end{array}$ \\
\hline
\end{tabular}


In view of the value of the dissociation constant, the decrease of $\Lambda$ with increasing concentration can be fundamentally attributed to an appreciable association at higher concentrations. On such a basis and assuming that the association takes place according to a simple ion-pair formation, a linear dependence of $\Lambda$ on $1 / \mathrm{c}^{1 / 2}$ must be approached in the concentration range where ionic association predominates. A $\log \Lambda v s \log c$ plot is shown in Fig. 4, and it may be observed that at the higher concentrations data approach asymptotically a straight line of slope $-0 \cdot 5$.

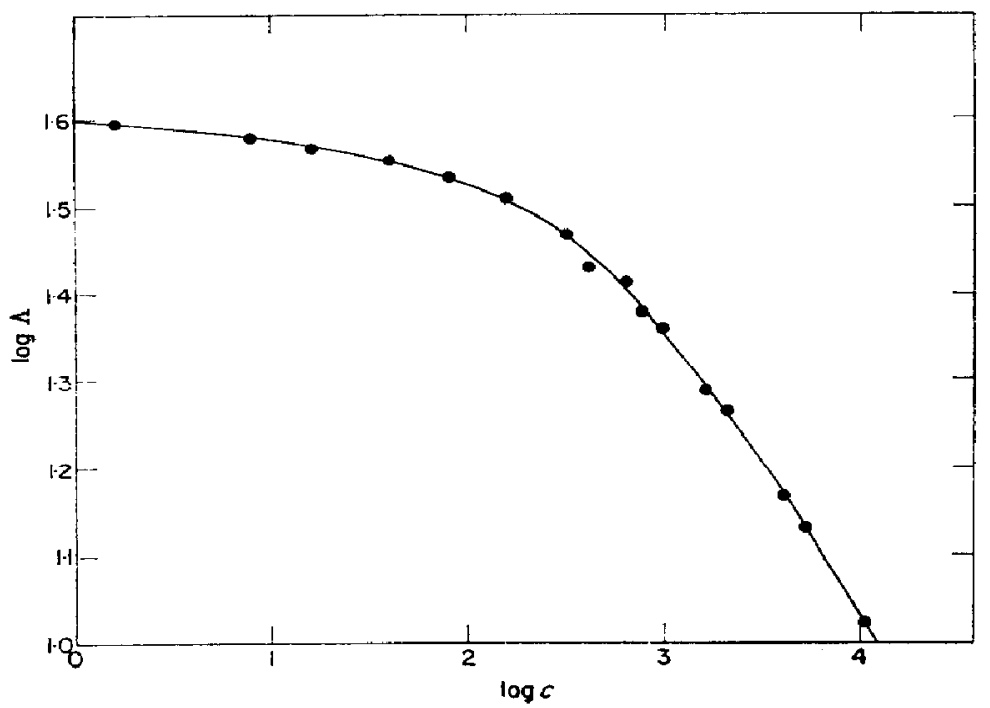

FIG. 4. Plot of $\log \Lambda v s \log c$.

On the other hand, it is possible to calculate, by applying Bjerrum's theory, ${ }^{20}$ the minimum distance for the formation of ion pairs. For a 1-1 electrolyte in DMSO, this distance is $6 \times 10^{-8} \mathrm{~cm}$; therefore for smaller distances, short range ion-pairs are evidently formed.

The figure for the molar limiting conductance is very similar to those of other 1-1 electrolytes in DMSO, such as the alkali perchlorates, suggesting that the mechanism of electrical conduction of hydrogen ion in DMSO must be pictured by a model in which charges are transported by simple entities in a viscous continuum, unlike the case of the hydrogen ion in aqueous medium, where the mechanism of electrical conduction involves the formation of hydrogen bridges.

On this account we can depict the ionization and ion-pair formation processes as follows,

$$
\begin{aligned}
& \mathrm{DMSO}+\mathrm{HCl} \leftrightarrows \mathrm{DMSOH} . \mathrm{HCl} \text {, } \\
& \mathrm{DMSOH} . \mathrm{HCl} \leftrightarrows \mathrm{DMSOH}^{+} \mathrm{Cl}^{-} \text {, } \\
& \mathrm{DMSOH}^{+} \mathrm{Cl}^{-} \leftrightarrows \mathrm{DMSOH}_{\text {(solv) }}^{+}+\mathrm{Cl}_{\text {(solv) }}^{-}
\end{aligned}
$$

Reaction (I) corresponds to the formation of the complex of the donor-acceptor type, (II) represents the rearrangement of an "outer" complex to an "inner" complex, according to Mulliken, ${ }^{21}$ and (III) accounts for the equilibrium related to the ionization of the complex, its magnitude determined by $K_{\mathrm{d}}$.

The sequence of equilibria mentioned above is similar to those found for other 
aprotic solvents such as pyridine, acetonitrile and benzonitrile. However, results in DMSO are less subject to criticism since no appreciable "time effect" has been found to obscure the experimental results.

Finally, it is interesting to compare $\Lambda_{0}$ values for $\mathrm{HCl}$ in different solvents as shown in Table 5. Taking into consideration the viscosity of the solvent and the

TABLE 5. $\Lambda_{\text {p }}$ For HCl IN DIFFERENT SOLVENTS

\begin{tabular}{|c|c|c|c|c|}
\hline Solvent & $\stackrel{\Lambda_{0}}{\text { int mho } \mathrm{cm}^{2} / \mathrm{mol}}$ & $\begin{array}{l}\eta_{0} \times 10^{2} \\
\mathrm{~g} / \mathrm{cms}\end{array}$ & $\begin{array}{l}\Lambda_{0} \eta_{0} \times 10^{2} \\
\text { int } \mathrm{mho} \mathrm{g} \mathrm{cm} / \mathrm{mols}\end{array}$ & $D_{25 \circ \mathrm{C}}$ \\
\hline DMSO & $38 \cdot 7$ & $2 \cdot 002$ & $77 \cdot 5$ & $46 \cdot 5$ \\
\hline Acetonitrile 10 & $32 \cdot 1$ & 0.345 & 11-1 & 35-99 \\
\hline Benzonitrile 11 & $1 \cdot 5$ & $1 \cdot 24$ & $1 \cdot 9$ & $25 \cdot 2$ \\
\hline Pyridine ${ }^{12}$ & 93 & 0.974 & $90 \cdot 6$ & $12 \cdot 3$ \\
\hline
\end{tabular}

Walden's constant, a difference of behaviour is observed. This cannot be accounted for by simple models representing the mechanism of conduction in media of intermediate dielectric constant. The results obtained in DMSO suggest that it would be worthwhile to check available data for the conductivity of $\mathrm{HCl}$ in solvents like acetonitrile, ${ }^{10,22}$ where large discrepancies outside experimental error have been reported.

Acknowledgement-This work has been supported in part by the Consejo Nacional de Investigaciones Cientificas y Técnicas of Argentina.

\section{REFERENCES}

1. J. A. Olabe, M. C. Giordano and A. J. Arvía, Electrochim. Acta 12, 907 (1967).

2. J. A. Olabe and A. J. Arví, Electrochim. Acta. 14, 785 (1969).

3. I. M. Kolthoff and T. B. ReDdY, J. electrochem. Soc. 108, 980 (1961).

4. J. A. Olabe and A. J. Arvif, Electrochim. Acta, in press.

5. J. N. BUTLER, J. electroanal. Chem. 14, 89 (1967).

6. J. A. Bolzan, M. C. Giordano and A. J. Arvia, Anl. Asoc. quim. Argent. 54, 171 (1966).

7. P. G. Sears, G. R. Lester and L. R. Dawson, J. phys. Chem. 60, 1433 (1956).

8. G. J. JANz and S. S. DanYluk, in Electrolytes, ed. B. Pesce, p. 255. Pergamon, London (1962).

9. G. Jones and B. C. Bradshaw, J. Am. chem. Soc. 55, 1780 (1933).

10. G. J. JANZ and S. S. Danyluk, J. Am. chem. Soc. 81, 3846 (1959).

11. G. J. Janz, I. Ahmad and H. V. Venkatasetry, J. phys. Chem. 68, 889 (1964).

12. H. Angerstein, Roczn. Chem. 30, 855 (1956).

13. J. E. Prue and R. J. Sherrington, Trans. Faraday Soc. 57, 1795 (1961).

14. R. M. Fuoss and C. A. Krauss, J. Am. chem. Soc. 55, 476 (1933).

15. R. M. Fuoss and T. Shedlovsky, J. Am. chem. Soc. 71, 1496 (1949).

16. R. M. Fuoss, J. Am. chem. Soc. 81, 2659 (1959).

17. R. M. Fuoss, J. Am. chem. Soc. 57, 488 (1935).

18. M. Falkenhagen and M. Dole, $Z$. phys. Chem. 6, 159 (1929).

19. M. Falkenhagen and M. Dole, Physik. $Z$. 30, 611 (1929).

20. N. BJERRUM, Danske Vidensk. Selskab. 7, (9) (1926).

21. R. S. Mulliken, J. phys. Chem. 56, 801 (1952); J. Am. chem. Soc. 74, 811 (1952).

22. V. A. Pleskov, Zh. fiz. Khim. 22, 351 (1948). 